Summary: Cell adhesion to a scaffold is a prerequisite for tissue engineering. Many studies have been focused on enhancing cell adhesion to synthetic materials that are used for scaffold fabrication. In this study, we applied an avidin-biotin binding system to enhance chondrocyte adhesion to biodegradable polymers. Biotin molecules were conjugated to the cell membrane of chondrocytes, and mediated cell adhesion to avidin-coated surfaces. We demonstrated that immobilization of biotin molecules to chondrocyte surfaces enhanced cell adhesion to avidin-coated biodegradable polymers such as poly(L-lactic acid), poly(D,L-lactic acid), and polycaprolactone, compared to the adhesion of normal chondrocytes to the same type of biodegradable polymer. The biotinylated chondrocytes still maintained their proliferation ability. This study showed the promise of applying the avidin-biotin system in cartilage tissue engineering.

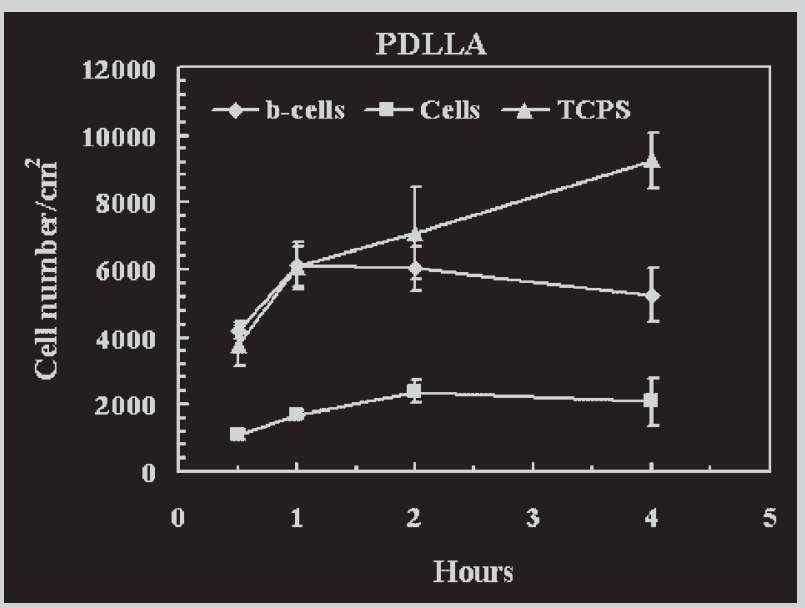

The adhesion of B-chondrocytes to avidin-adsorbed surfaces (PDLLA) in serum-free medium $(\checkmark)$ and that of normal chondrocytes to untreated surfaces in the serum-containing media ( $\square$ ) (control: adhesion of normal chondrocytes to untreated TCPS in the serum-containing medium $(\boldsymbol{\Delta})$ ).

\title{
Effects of an Avidin-Biotin Binding System on Chondrocyte Adhesion and Growth on Biodegradable Polymers
}

\author{
Wei-Bor Tsai,* Min-Cheng Wang
}

Department of Chemical Engineering, National Taiwan University, No. 1, Roosevelt Road, Sec. 4, Taipei, 106, Taiwan Fax: 886-2-2362-3040; E-mail: weibortsai@ntu.edu.tw

Received: September 12, 2004; Revised: December 3, 2004; Accepted: December 7, 2004; DOI: 10.1002/mabi.200400144

Keywords: avidin-biotin; biodegradable; cell adhesion and growth; chondrocytes; polyesters

\section{Introduction}

In the field of tissue engineering, scaffolds play a role like extracellular matrix $(\mathrm{ECM})$ in natural tissues, which support cell attachment, proliferation, differentiation, and migration. The architectural design of scaffolds, mimicking ECM, is usually a highly porous and three-dimensional structure that allows enough cells to accommodate and grow inside, and organizes cells to form a tissue. ${ }^{[1]}$ Cell attachment to a scaffold is a prerequisite for a successful tissue engineering outcome. ${ }^{[1]}$ The retained cells then proliferate and secrete ECM macromolecules to replace the gradually degraded scaffold. A new tissue is formed after the scaffold disappears.
A biodegradable synthetic polymer has been one of favorable materials used for fabricating scaffolds. The advantages of synthetic biodegradable polymers include controllable degradation rate, high reproducibility, and easy fabrication into specific shapes. ${ }^{[2]}$ A variety of synthetic biodegradable materials has been explored to fabricate as scaffolding for cartilage tissue engineering, including polyesters like poly(L-lactic acid) (PLLA), poly(glycolic acid) (PGA), their copolymer (PLGA), and polycaprolactone (PCL).

In native tissues, cells attach to their surrounding ECM via membrane receptors (e.g., integrins ${ }^{[3]}$ ) that specifically bind to ECM adhesion proteins such as fibronectin, vitronectin, and laminin. ECM adhesion proteins possess cell 
binding domain peptide sequences such as RGD and YIGSR, which bind specifically to cell membrane receptors. ${ }^{[4]}$ However, synthetic biomaterials lack ECM adhesion proteins or peptides for specific interactions with cell membrane receptors, so cell attachment to artificial biomaterials is merely mediated by non-specific interactions such as ionic attraction, hydrogen bonding, and hydrophobic interaction between cell membrane components and substrata. As a result, cells may adhere poorly to synthetic biomaterials, subsequently hampering the outcome of tissue engineering products. Therefore promoting cell adhesion to synthetic biomaterials has long been the focus of much research.

Several strategies improve affinities between cells and synthetic surfaces. The most favored method is to physically adsorb or chemically conjugate ECM adhesion proteins to biomaterial surfaces. ${ }^{[5-7]}$ Alternatively, conjugating peptides containing cell-binding sequences (e.g., RGD) also improve cell adhesion to biomaterials. ${ }^{[8-10]}$ The above approaches are based on the formation of integrinmediated bonds between cell adhesion molecules on substrata and integrin receptors in cell membrane. Therefore, the efficacy of these approaches will depend on the availability of cell-membrane receptors. Cells possessing few functional integrins might not benefit from the above methods.

The above issue could be solved by using a binding mechanism irrelevant to the integrin-binding system. For example, precoating of biomaterial surfaces with antibodies against cell membrane antigens improved cell adhesion onto biomaterials. ${ }^{[1,12]}$ Another approach utilizes a pair of molecules, which bind to each other. One of them is conjugated to cell membrane, and the other one is immobilized to biomaterial surfaces. The bond formation between these two molecules could mediate cell adhesion to biomaterial surfaces. A good example of binding molecule pairs is avidin and biotin. Avidin is a glycoprotein found in egg white, and has multiple binding sites for biotin (vitamin $\mathrm{H})$. A major distinguishing feature for the avidin-biotin system is its extraordinarily high affinity (the affinity constant $\left.K_{a} 10^{13-15} \mathrm{M}^{-1}\right)$. ${ }^{[13]}$ Avidin-biotin technology has been extensively applied to biotechnology, such as affinity chromatography, histochemistry, diagnostics, immunoassay, and drug delivery. ${ }^{[14]}$ The feasibility of introducing an avidin-biotin binding system for increasing cell attachment has been verified previously. A non-adhesive cell line Ehrilich ascites carcinoma was converted to anchoragedependent cells by conjugation of biotin molecules on cell membrane. ${ }^{[15]}$ The biotinylated cells not only adhered to avidin-coated substrata, but also underwent spreading which involves rearrangement of the cytoskeleton, organization of focal contacts, and attainment of cell morphology.

Reichert's group at Duke University has explored the application of the avidin-biotin binding system to a real biomedical problem. Synthetic vascular grafts with small diameters suffer from occlusion caused by thrombosis. ${ }^{[16]}$ The patency of small synthetic vascular grafts could be improved by the retention of an endothelial cell layer in the graft lumen. ${ }^{[17,18]}$ Reichert's group showed that conjugation of biotin molecules to bovine aortic endothelial cells enhanced initial cell attachment to avidin-treated surfaces, ${ }^{[19-24]}$ cell spreading rate, and the strength of cell attachment. $^{[21]}$ It was suggested that the avidin-biotin system not only helps cell adhesion directly, but also brings cell membrane in close proximity to substrata, which accelerates integrin-mediated linkages between cell membrane integrins and surface-adsorbed serum adhesion proteins. ${ }^{[21]}$ Reichert's studies showed great promise to establish a viable endothelial cell layer in polymeric vascular grafts by the high affinity avidin-biotin binding system.

The aim of the current study was to explore the possibility of using the avidin-biotin binding system in tissue engineering application. One general procedure for articular cartilage tissue engineering starts from the expansion of autologous chondrocytes, and the cells are then seeded into a biodegradable scaffold. After cultured in vitro for a period of time, the newly formed cartilage is used to repair the patient's injured articular cartilage. In this study, we intended to utilize the avidin-biotin binding system in enhancing chondrocyte adhesion to several types of synthetic biodegradable polymers, which is commonly used in fabricating scaffolds. Cell adhesion and cell proliferation were evaluated in this study.

\section{Experimental Part}

\section{Biodegradable Polymers}

Poly(lactide-co-glycolide) 85:15 w/w (PLGA) and poly(D,Llactide) (PDLLA) were synthesized via ring-opening polymerization in bulk. $0.01 \%$ Lauryl alcohol and $0.03 \%$ stannous octoate were applied as a chain control agent and catalyst, respectively. Polymerization was carried out for $6 \mathrm{~h}$ at $180^{\circ} \mathrm{C}$. The molecular weights of PLGA and PDLLA were determined by GPC (Thermo Separation system P1000, U.S.) using tetrahydrofuran as eluent and polystyrene as calibration standards. For PLGA, the determined molecular weights were $\bar{M}_{\mathrm{n}}$ 10723 and $\bar{M}_{\mathrm{w}} 30986$; for PDLLA, they were $\bar{M}_{\mathrm{n}} 88341$ and $\bar{M}_{\mathrm{w}} 131140$. PLLA (I.V. $8.41 \mathrm{dl} \cdot \mathrm{g}^{-1}$ ) were purchased from PURAC, Inc. PCL was obtained from Aldrich (Cat. no. 440744, $\left.\bar{M}_{\mathrm{n}}=80000\right)$.

Each polymer was dissolved in dichloromethane to a $25 \mathrm{mg} \cdot \mathrm{ml}^{-1}$ solution and $100 \mu \mathrm{l}$ per well of polymer solution was added to poly(propylene) 96-well plates (Cat. no. 3364, Corning, USA). Polymer films were formed after dichloromethane evaporation in a fume hood overnight, and the residual solvent was further removed in a vacuum oven. The polymer-coated wells were ready for experiments after sterilized with $70 \%$ ethanol and exposed to UV overnight.

Surface hydrolysis of PDLLA or PLLA samples was carried out by incubating samples in a $0.05 \mathrm{M}$ sodium hydroxide solution for $15 \mathrm{~min}$. Subsequently each sample was rinsed with MilliQ water several times. 


\section{Chondrocyte Isolation}

Articular cartilage samples were dissected aseptically from pig (nine to ten months old) knee joints, which were obtained from a local abattoir. The articular cartilage samples were diced into approximate $1 \mathrm{~mm}^{3}$ pieces in autoclaved PBS (phosphate buffered saline, $137 \mathrm{~mm} \mathrm{NaCl}, 2.7 \mathrm{~mm} \mathrm{KCl}, 10 \mathrm{~mm} \mathrm{Na}_{2} \mathrm{HPO}_{4}$, and $1.8 \mathrm{mM} \mathrm{KH}_{2} \mathrm{PO}_{4}$ ) containing $200 \mu \mathrm{g} \cdot \mathrm{ml}^{-1}$ gentamicin (Gibco, Cat. no. 1570064) and $25 \mu \mathrm{g} \cdot \mathrm{ml}^{-1}$ fungizone (Gibco, Cat. no. 1520018). After rinsed with PBS three times, $1 \sim 2 \mathrm{~g}$ of the cartilage slivers were digested in $10 \mathrm{ml}$ of DMEM/F12 (Gibco, Cat. no. 12400-024) containing $1 \mathrm{mg} \cdot \mathrm{ml}^{-1}$ hyaluronidase (Sigma, Cat. no. $\mathrm{H}-3506$ ) and $1 \mathrm{mg} \cdot \mathrm{ml}^{-1}$ type I collagenase (Sigma, Cat. no. C0130) in a $37^{\circ} \mathrm{C}, 5 \% \mathrm{CO}_{2}$ incubator for $18 \mathrm{~h}$. The digestate was filtered through a $70-\mu \mathrm{m}$ filter cell strainer (Falcon, Cat. no. 352350) to remove undigested cartilage lumps. The filtrate was then centrifuged at $200 \mathrm{~g}$ for $10 \mathrm{~min}$, and the cell pellet was resuspended in chondrocyte medium (DMEM/F12 supplemented with $2.5 \mathrm{~mm}$ L-glutamine, $200 \mu \mathrm{g} \cdot \mathrm{ml}^{-1}$ gentamicin, $25 \mu \mathrm{g} \cdot \mathrm{ml}^{-1}$ fungizone, and $10 \%$ bovine calf serum). Cell number and viability were determined using a hemocytometer with trypan blue exclusion. The freshly-isolated cells were seeded in T75 flask, grown to confluence, and then retrieved using trypsin treatment. Chondrocytes at passage one were used in this study.

\section{Biotinylation of Chondrocytes}

Biotinylation of porcine chondrocytes was performed according to a method using water soluble $N$-hydroxysulfosuccinimidobiotin (3-Sulfo-NHS-Biotin, Sigma, Cat. no. B5161). ${ }^{[25]}$ The NHS moiety will react with primary amino groups $\left(-\mathrm{NH}_{2}\right)$ to form stable amide bonds, so biotin molecules could be conjugated to cell membrane proteins via the amide bonds formed between NHS and free amine groups, primarily the epsilon amine group of lysine residue in proteins. Briefly, 3-Sulfo-NHS-Biotin was added to chondrocyte solution $\left(10^{6}\right.$ cells $\cdot \mathrm{ml}^{-1}$ in PBS) to a ratio of $1 \mathrm{mg}$ per $10^{6}$ cells. The mixture was incubated in ice for $30 \mathrm{~min}$ and then washed twice with PBS by repeating centrifugation and re-suspension. The biotinylated chondrocytes (B-chondrocytes) was visualized by fluorescence microscopy after incubated with $1 \mathrm{mg} \cdot \mathrm{ml}^{-1}$ avidin-FITC (Sigma, A-2901) for $5 \mathrm{~min}$. The extent of biotinylation was determined using the 4'-hydroxyazobenzene-2-carbocylic acid (HABA) assay as described previously. ${ }^{[20]}$ Briefly, B-chondrocytes were incubated in avidin-HABA reagent $(10 \mathrm{mg}$ of avidin and $600 \mu \mathrm{l}$ of $10 \mathrm{~mm}$ HABA (Cat. no. 28010, Pierce) in $10 \mathrm{~mm} \mathrm{NaOH}$ added to $19.4 \mathrm{ml}$ of PBS) for $5 \mathrm{~min}$. After centrifugation, the absorbance of the supernatant at $490 \mathrm{~nm}$ was measured. A series of known amounts of biotin solution was used to prepare a calibration curve for determining the unknown amount of biotin molecules on cell membrane.

\section{Adhesion of B-Chondrocytes}

The substrates were coated with $50 \mu \mathrm{l}$ per well of $0.1 \mathrm{mg} \cdot \mathrm{ml}^{-1}$ avidin solution in PBS and incubated at room temperature for $1 \mathrm{~h}$. After the avidin-coated surfaces were rinsed with PBS twice, B-chondrocytes were seeded in serum-free medium, while normal chondrocytes were seeded to untreated surfaces in serum-containing medium. As a control, normal chondrocytes were seeded to TCPS in serum-containing medium. At different time points, the number of adherent cells was determined by a Hoechst 33258 assay. ${ }^{[26]}$ Briefly, the adherent chondrocytes were lysed by 10 mM EDTA in deionized water $\left(\mathrm{pH}\right.$ 12.0) and then neutralized with $1 \mathrm{~N} \mathrm{KH}_{2} \mathrm{PO}_{4}$ solution ( $\mathrm{pH}$ 4.0). One hundred microliters of cell lysate were mixed with $1 \mathrm{ml}$ of $50 \mathrm{mg} \cdot \mathrm{ml}^{-1}$ Hoechst 33258 solution in $\mathrm{H}_{2} \mathrm{O}$ and then the fluorescence at $456 \mathrm{~nm}$ was measured at the excitation wavelength $348 \mathrm{~nm}$. A series of known numbers of chondrocytes (determined by a hemocytometer) was used to generate a calibration curve, and the numbers of adherent cells were determined by interpolation.

\section{Cell Growth}

Twenty-four hours after cell seeding, unattached cells were rinsed away with PBS for thrice, and the wells were filled with fresh serum-containing chondrocyte medium. Chondrocyte medium was changed every 2 or $3 \mathrm{~d}$. Cell number after 3 or $7 \mathrm{~d}$ incubation was determined by the Hoechst 33258 method as described above. Cell doubling time was calculated by the following equation: $N_{t}=N_{0} \times 2^{t / d}$, where $N_{t}$ is the cell number on time $t, N_{0}$ is the initial cell number, and $d$ is the doubling time.

\section{Statistics}

Statistical assessment of significant variations was performed by GraphPad Instat ${ }^{\circledR} 3.00$ (GraphPad Software, Inc.). Welch corrected unpaired $t$-test was conducted to determine $p$-values. All data were reported as mean $\pm \mathrm{SD}$.

\section{Results}

\section{Chondrocyte Biotinylation}

After biotinylation, B-chondrocytes were immediately incubated with avidin-FITC. All B-chondrocytes had green appearance under a fluorescence microscope (Figure 1A,B), while the control untreated cells did not show any fluorescence (images not shown). The binding of avidinFITC to B-chondrocytes indicated the success of biotinylation. The extent of biotinylation was determined to be $3.21 \pm 0.68 \times 10^{9}$ biotin molecules per cell $(n=10)$. The viability of B-chondrocytes was beyond $95 \%$.

\section{Effect of Partial Hydrolysis of PDLLA or PLLA Surface on Cell Adhesion}

Partial hydrolysis of polyester surfaces changes surface hydrophilicity, and in turn influences protein adsorption and cell attachment. ${ }^{[27]}$ Therefore, we first evaluated the effect of $\mathrm{NaOH}$ treatment to PDLLA and PLLA surfaces on cell adhesion before studying the adhesion of B-chondrocytes. Figure 2 shows that the incubation of PDLLA or PLLA in 

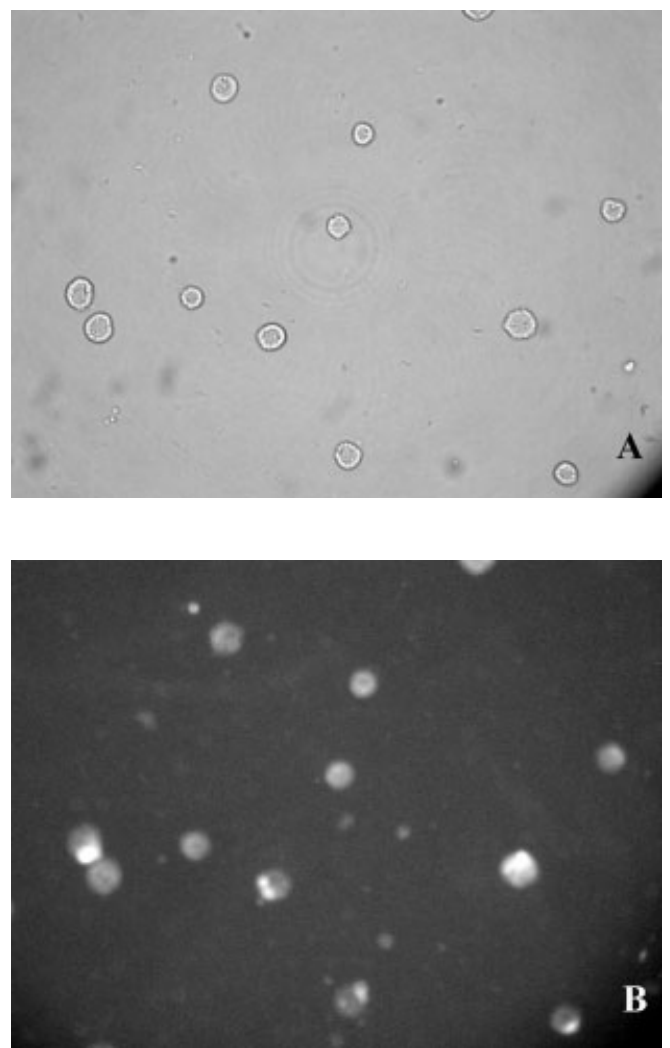

Figure 1. Phase contrast microphotograph (A) and fluorescent microphotograph (B) of biotinylated chondrocytes (B-chondrocytes) immediately after biotinylation $(200 \times)$. The fluorescent image was taken immediately after incubation with avidin-FITC $\left(1 \mathrm{mg} \cdot \mathrm{ml}^{-1}\right)$ for $5 \mathrm{~min}$.

$\mathrm{NaOH}$ solution did not influence the adhesion of untreated chondrocytes or B-chondrocytes $(P>0.05)$. Therefore, in the following experiments, biodegradable polymer surfaces were not pre-treated with $\mathrm{NaOH}$ solution.

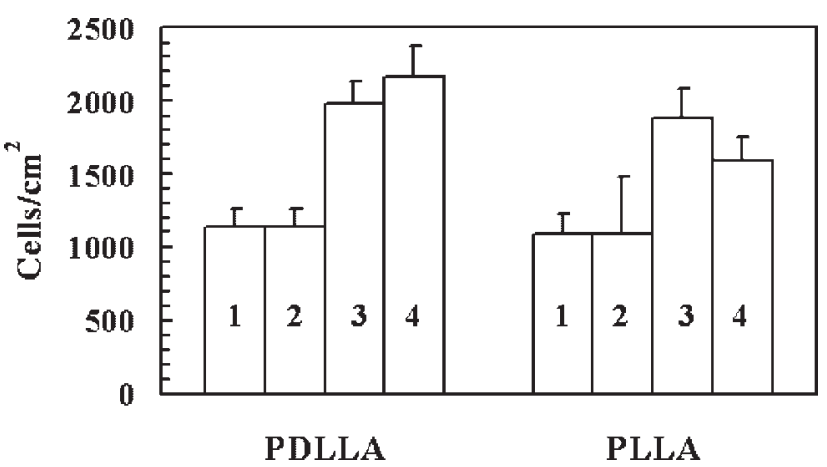

Figure 2. The effect of $\mathrm{NaOH}$ treatment to poly(D,L-lactide) (PDLLA) and poly(L-lactic acid) (PLLA) on chondrocyte adhesion for 2 h. 1. Normal chondrocytes $+\mathrm{NaOH}$ untreated surface; (2) normal chondrocytes $+\mathrm{NaOH}$ treated surface; (3) B-chondrocytes $+\mathrm{NaOH}$ untreated surface; (4) B-chondrocytes $+\mathrm{NaOH}$ treated surface. $n=4$.

\section{Effect of Seeding Conditions on the Adhesion of $B$-Chondrocytes to PDLLA and PLLA}

Figure 3 shows the 2-h adhesion of normal chondrocytes or B-chondrocytes to PDLLA (Figure 3A) or PLLA (Figure 3B) at various conditions. It is generally thought that adsorption of serum adhesion proteins, such as fibronectin and vitronectin, to synthetic substrates enhances cell adhesion. However, we found that the 2-h adhesion of normal chondrocytes was higher in serum-free medium than in the serum-containing medium (comparing bars 1 and 2 in Figure $3 \mathrm{~A}$ or $\mathrm{B}, P<0.01)$. We suspect that adsorption of serum passive proteins such as albumin might inhibit cell adhesion. In the presence of serum, the adhesion of Bchondrocytes and normal chondrocytes to the surfaces untreated with avidin was comparable (comparing bars 2 and 3 in Figure $3 \mathrm{~A}$ or $\mathrm{B}, P>0.05$ ). There was no significant
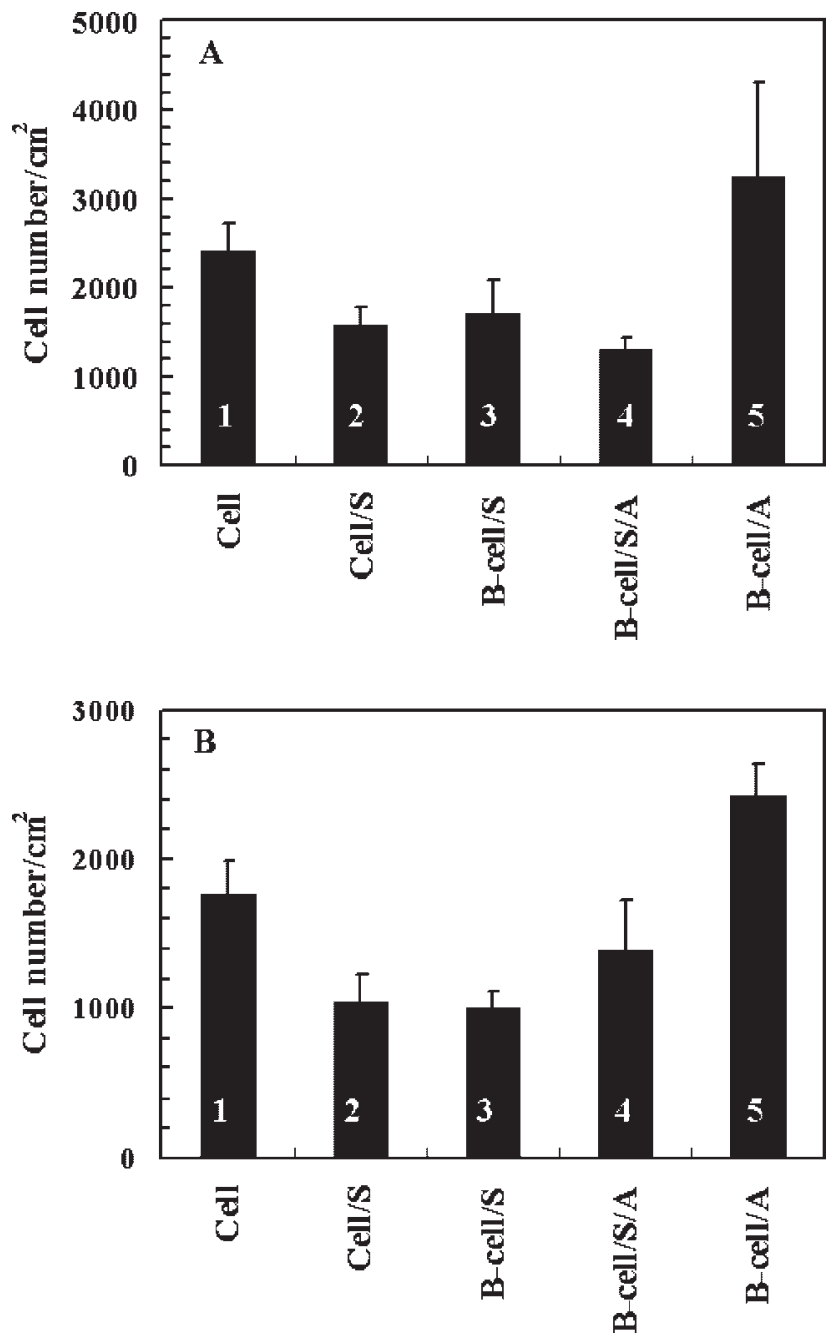

Figure 3. The effect of seeding conditions on the adhesion of B-chondrocytes. To PDLLA (A) and PLLA (B) for $2 \mathrm{~h}$. Cell, normal chondrocytes; B-cell, biotinylated chondrocytes; S, serum-containing medium; A, avidin-coated surface. $n=4$. 
difference between B-chondrocyte adhesion to avidincoated or -uncoated surfaces in the presence of serum (comparing bars 3 and 4 in Figure $3 \mathrm{~A}$ or $\mathrm{B}, P>0.05$ ). In contrast, B-chondrocytes adhered to the avidin-coated surfaces significantly better in the absence of serum than in the presence of serum (comparing bars 4 and 5 in Figure $3 \mathrm{~A}$ or $\mathrm{B}, P<0.01)$. B-chondrocyte adhesion to the avidin-coated surfaces in the absence of serum was also significantly better than normal chondrocyte adhesion to the untreated substrates, either in the presence of serum (comparing bars 2 and 5 in Figure $3 \mathrm{~A}$ or $\mathrm{B}, P<0.05$ ) or in the absence of serum (only on PLLA, comparing bars 1 and 5 in Figure 3B, $P<0.01)$.

\section{Chondrocyte Adhesion and Growth}

First of all, we studied the adhesion of B-chondrocytes in a short time course (4 h). The adhesion of B-chondrocytes to PDLLA (Figure 4A) or PLLA (Figure 4B) was significantly higher than that of untreated chondrocytes during the whole period $(P<0.001)$. The initial adhesion of B-chondrocytes (half or $1 \mathrm{~h}$ ) was compared to that of untreated chondrocytes to TCPS surfaces. However, B-chondrocytes adhesion reached a plateau very quickly. B-chondrocytes adhesion was not increased after $1 \mathrm{~h}$. In contrast, cell adhesion to TCPS was increased with time (the triangle symbols in Figure 4A and B). Figure 5 shows adhesion of B-chondrocytes to two other kinds of biodegradable polymers: PLGA and PCL. Generally, the biotinylation strategy also enhanced chondrocyte adhesion to these two surfaces. However, the enhancement in cell adhesion to PLGA was significant only at the 2 -h point $(P<0.05$, Figure $5 \mathrm{~A})$. On the other hand, biotinylation enhanced cell adhesion to PCL significantly $(P<0.05$, Figure 5B).

Cell growth was evaluated by determining cell number on day 1 , day 3 , and day 7 . First, we found that even though the cell number of adherent B-chondrocytes was significantly higher than that of untreated chondrocytes $4 \mathrm{~h}$ after adhesion on PDLLA (Figure 4A) or PLLA (Figure 4B), after $24 \mathrm{~h}$ the difference in cell number was not significant (comparing the diamond and the square symbols in Figure $6 \mathrm{~A}$ or B, $P>0.05$ ). Secondly, B-chondrocytes grew faster than untreated chondrocytes. On day 7 , the number of adherent B-chondrocytes was significantly higher than that of untreated chondrocytes (Figure 6A and B, $P<0.001$ ). The doubling times for B-chondrocytes and untreated chondrocytes on PDLLA and PLLA, and untreated chondrocytes on TCPS are listed in Table 1. On PDLLA, the growth rate of B-chondrocytes was higher than that of untreated chondrocytes, while on PLLA, the growth rates for the two types of cells were comparable.

The cultured B-chondrocytes were incubated with avidin-FITC on day 1 , day 3 , and day 7 to trace the membrane-bound biotin molecules. Many adherent B-chondrocytes already lost their surface biotin moieties on day 1
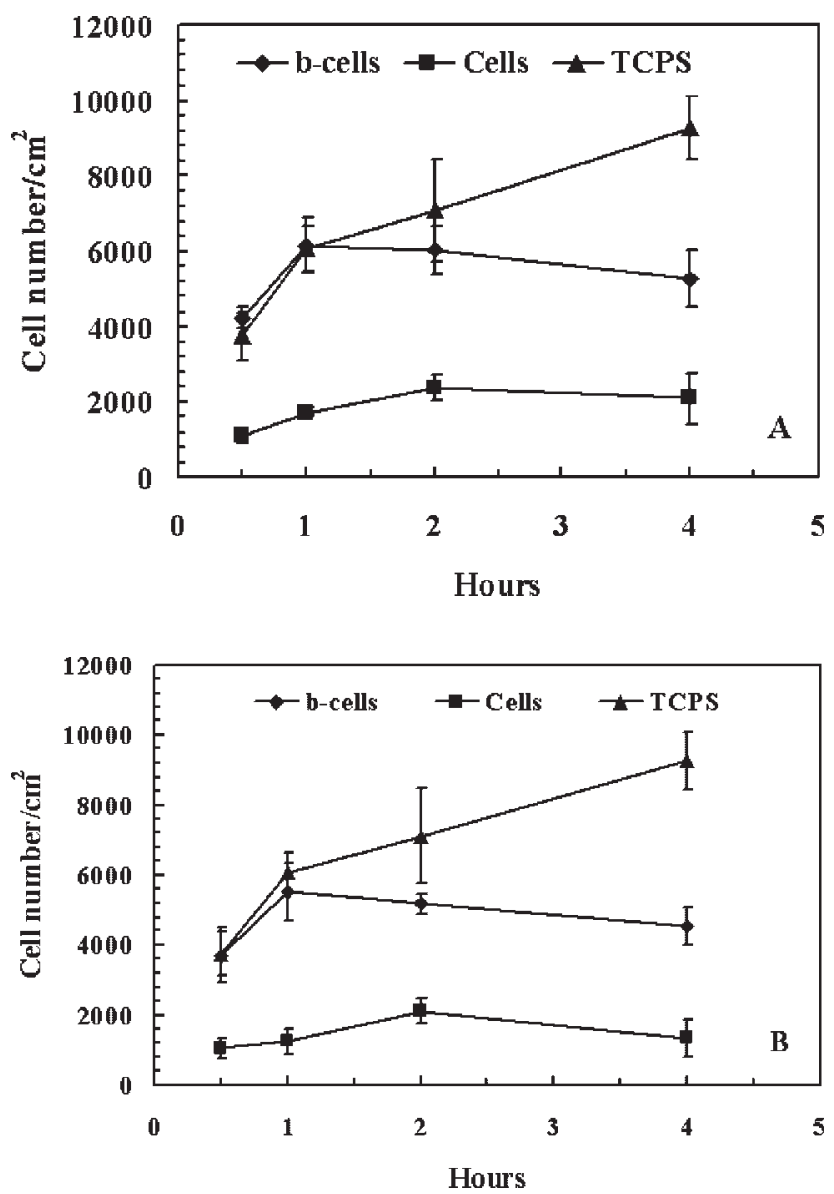

Figure 4. The adhesion of B-chondrocytes to avidin-adsorbed surfaces in serum-free medium $(\bullet)$ and that of normal chondrocytes to untreated surfaces in the serum-containing media ( $\square$ ) at the indicated time points. The control was the adhesion of normal chondrocytes to untreated TCPS in the serum-containing medium (A). A: PDLLA; (B) PLLA. $n=4$.

(Figure 7A and $\mathrm{B}$ ), and after day 3 almost none of the adherent B-chondrocytes showed any fluorescence (images not shown).

\section{Discussion}

Compared to TCPS, which is routinely used in cell culture laboratories, synthetic biodegradable polymers, such as PLLA, PDLLA, PLGA, or PCL, did not support chondrocyte adhesion well (e.g., comparing the triangle and the square symbols in Figure 4A and B). We demonstrated that conjugation of biotin molecules to cell membrane enhanced cell adhesion to the avidin-coated PDLLA, PLLA, and PCL (comparing the diamond and the square symbols in Figure 4A, 4B, and 5B). However, the enhancement in cell adhesion was not significant on PLGA (Figure 5A), suggesting that the effect of biotinylation on cell adhesion is dependent on surface type. The adhesion of B-chondrocytes to avidin-coated surfaces was comparable to the adhesion of 

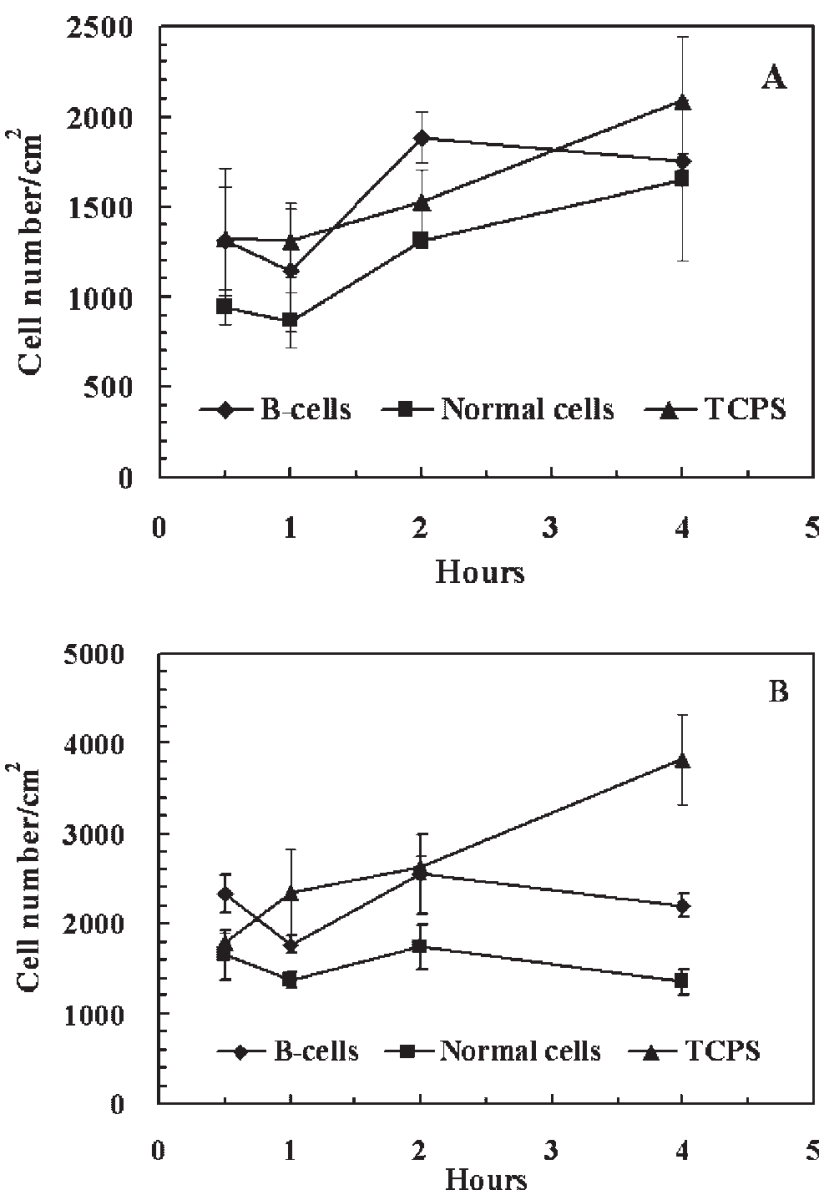

Figure 5. The adhesion of B-chondrocytes to avidin-adsorbed surfaces in serum-free medium $(\diamond)$ and that of normal chondrocytes to untreated surfaces in the serum-containing media ( $\boldsymbol{\square})$ at the indicated time points. The control was the adhesion of normal chondrocytes to untreated TCPS in the serum-containing medium $(\mathbf{\Delta})$. A: Poly(lactide-co-glycolide) (PLGA); (B) polycaprolactone (PCL). $n=4$.

untreated chondrocytes to TCPS during short adhesion time $(<1 \mathrm{~h})$ (Figure 4A, 4B, 5A, and 5B).

Conjugation of biotin molecules to cell membrane proteins provides an effective mechanism for cell adhesion to avidin-coated surfaces, which is contributed by high binding affinity between avidin and biotin. The affinity constant for the avidin-biotin binding $\left(K_{a}=10^{13-15} \mathrm{M}^{-1}\right)$ is several orders higher than the typical affinity constant between integrin receptors and ECM adhesive proteins $\left(K_{a}=\right.$ $\left.10^{6-9} \mathrm{M}^{-1}\right) \cdot{ }^{[28]}$ Cell adhesion strength has been suggested to be related to the log of the affinity constant. ${ }^{[29]}$ Therefore, the avidin-biotin binding system would increase cell adhesion strength by several folds over typical integrin binding systems for the same amount of bonds. It was reported that the adhesion strength of biotinylated endothelial cells was significantly higher than that of non-modified cells. ${ }^{[21]}$ The high affinity avidin-biotin binding system increased initial cell adhesion, cell spreading rate, and strength of cell attachment. $^{[21]}$
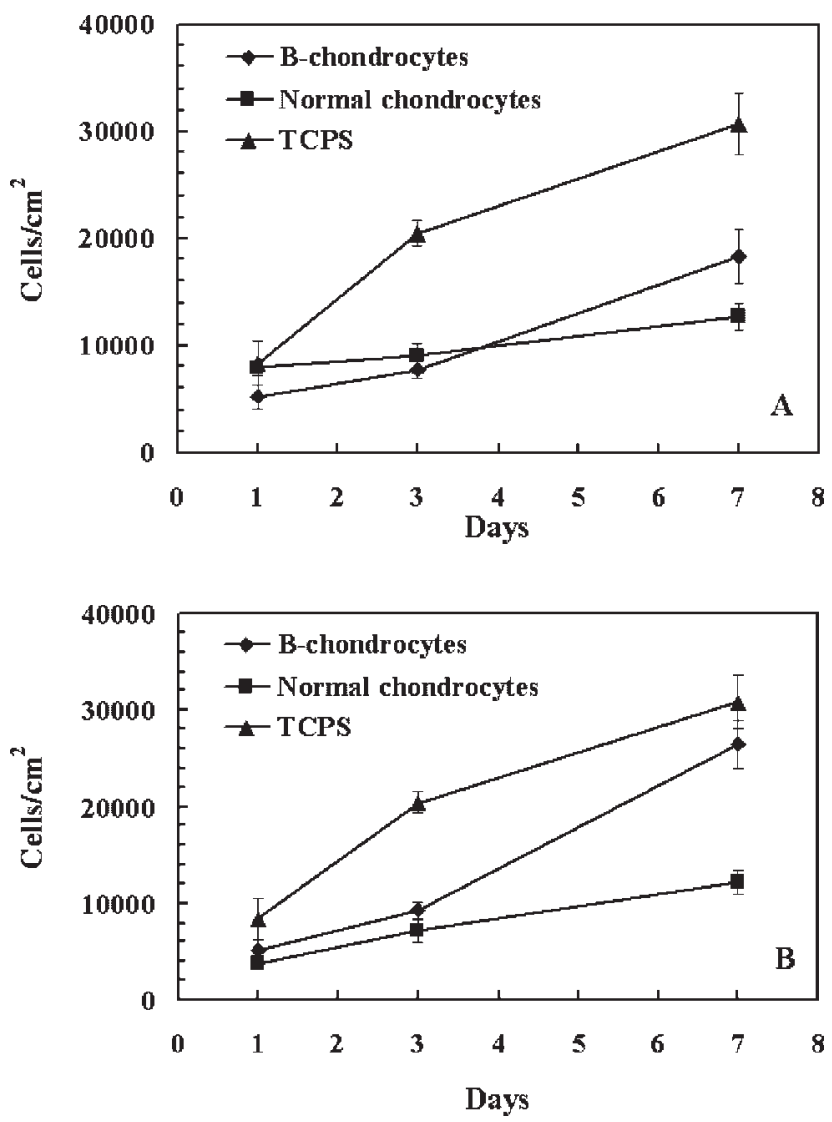

Figure 6. The growth curves for B-chondrocytes $(\diamond)$ that were seeded to avidin-coated surfaces in serum-free media, and normal chondrocytes $(\boldsymbol{\square})$ that were seeded to bare surfaces in serum-containing media. The control was normal chondrocytes that were seeded to untreated TCPS in the serumcontaining medium $(\mathbf{\Delta})$. The next day all media were replaced with fresh serum-containing media. Chondrocyte media were then changed every 2 or 3 d. A: PDLLA; (B) PLLA. $n=4$.

However, we found that the impetus of the avidin-biotin binding system in mediating cell adhesion did not seem long lasting in this study. In the 4-h adhesion experiments, B-chondrocyte adhesion was not increased after $1 \mathrm{~h}$

Table 1. The doubling time for normal chondrocytes and biotinylated chondrocytes (B-chondrocytes) on poly(D,L-lactide) (PDLLA), poly(L-lactic acid) (PLLA), and TCPS.

\section{Doubling times}

d

Day 1-day 3 Day 3-day 7

\begin{tabular}{llrl}
\hline PDLLA & Normal chondrocytes & 10.55 & 8.20 \\
& B-chondrocytes & 3.47 & 3.24 \\
PLLA & Normal chondrocytes & 2.19 & 5.18 \\
& B-chondrocytes & 2.35 & 2.64 \\
TCPS (normal chondrocytes) & 1.55 & 6.81
\end{tabular}



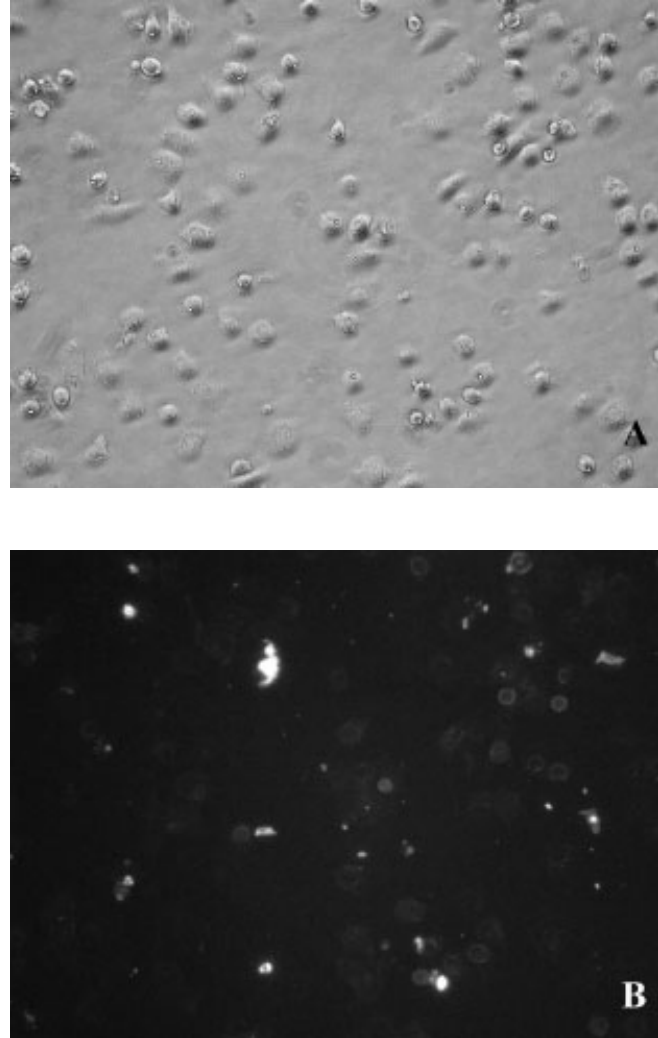

Figure 7. Phase contrast microphotograph (A) and fluorescent microphotograph (B) of adherent B-chondrocytes on day 1 $(200 \times)$. The fluorescent image was taken after incubation with avidin-FITC $\left(1 \mathrm{mg} \cdot \mathrm{ml}^{-1}\right)$ for $5 \mathrm{~min}$.

(PDLLA and PLLA) or $2 \mathrm{~h}$ (PLGA and PCL). In contrast, the adhesion of untreated cells to TCPS was increased with time during the whole 4-h period (square or triangle symbols in Figure 4A, 4B, 5A, and 5B). The results indicated that the efficacy of the avidin-biotin binding system in enhancing cell adhesion was only transient, while the integrin-dependent binding system provided a long-term mechanism for cell adhesion. The transient effects of the avidin-biotin system in mediating cell adhesion might be contributed to the endocytosis of biotin molecules. It has been reported that fluorescein-labeled avidin bound throughout the biotinylated cells, but shifted to cell interior in $24 \mathrm{~h}^{\left[{ }^{[25]}\right.}$ We also found that the biotin moieties on B-chondrocyte membrane was greatly decreased after 1-day incubation (Figure 7B) and was not detectable on day 3. Endocytosis of biotin molecules deprives the availability of biotin molecules on cell membrane and limits bond formation with surface-bound avidin. To further improve the efficacy of the avidin-biotin binding system, delay of biotin internalization might be a good strategy.

One rationale in using the avidin-biotin binding system is based on the premise that the biotin-conjugated cells will not be changed significantly in their intrinsic biological and physicochemical properties, such as cell attachment via the integrin-dependent mechanism, and cell proliferation. By comparing the bars 1 and 2 in Figure $3 \mathrm{~A}$ or B, B-chondrocyte adhesion to bare substrate in the serum-containing medium was comparable to that of normal chondrocytes, suggesting that conjugation of small biotin molecules to cell-membrane proteins did not influence their intrinsic ability in mediating cell adhesion. Therefore, B-chondrocyte adhesion to avidin-coated substrates might be further increased with the assistance of serum adhesion proteins. Previously, Reichert's group showed that combination of the avidin-biotin binding system and the intrinsic integrindependent adhesion systems further enhanced initial endothelial cell adhesion and spreading, ${ }^{[20]}$ focal contact area, and resistance to flow. ${ }^{[24]}$ Therefore, we would expect that B-chondrocyte adhesion to avidin-coated surfaces should be enhanced in serum-containing medium compared to serum-free medium. Surprisingly, B-chondrocyte adhesion to avidin-coated surfaces was much lower in serumcontaining condition than in serum-free condition (comparing bars 4 and 5 in Figure $3 \mathrm{~A}$ and $\mathrm{B}, P<0.01)$. One explanation is that sugar moieties on avidin molecules may lead to non-specific or other undesired interactions with serum proteins. ${ }^{[30]}$ Non-specific binding of serum proteins (especially passive proteins) to surface-bound avidin might hinder B-chondrocyte adhesion. Nevertheless, the avidinbiotin binding system provides a good tool in cell seeding at serum-free seeding condition when long-term serum-free culture is desired, a topic of interest in tissue engineering applications.

Another concern in using the avidin-biotin binding system in tissue engineering application is if B-chondrocytes still sustain proliferation ability. We showed that the growth rates of B-chondrocytes were comparable to those of untreated cells (Table 1). Although the surface was coated with avidin and the progeny of B-chondrocytes did not possess surface-bound biotin, the cells still adapted to the surfaces very well. It is possible that the avidin-adsorbed surfaces might be modulated by serum proteins or cellsecreted proteins, and then suitable for cell growth.

The study demonstrated the potential of the avidin-biotin binding system in enhancing cell adhesion in tissue engineering application. Currently, the utilization of this system in cell seeding and culture in 3-D scaffolds is under investigation in our laboratory. The results will be the subject of a separate report.

\section{Conclusion}

The high-affinity avidin-biotin binding system enhanced initial chondrocyte adhesion to biodegradable polymers such as PDLLA, PLLA, and PCL. Biotinylated cells still maintained proliferation ability. In conclusion, the current study demonstrated the applicability of the avidin-biotin system in cartilage tissue engineering. 
Acknowledgements: The authors thank National Science Council, ROC (NSC-91-2218-E-002-032) for financial support.

[1] J. A. Hubbell, Biotechnology 1995, 13, 565.

[2] L. E. Freed, G. Vunjak-Novakovic, R. J. Biron, D. B. Eagles, D. C. Lesnoy, S. K. Barlow, R. Langer, Biotechnology 1994, $12,689$.

[3] R. O. Hynes, Cell 1992, 69, 11.

[4] J. A. Hubbell in: "Principles of Tissue Engineering", R. P. Lanza, R. Langer, J. Vacanti, Eds., Academic Press, London 2000, p. 237.

[5] M. Balcells, E. R. Edelman, J. Cell. Physiol. 2002, 191, 155.

[6] A. Kikuchi, H. Taira, T. Tsuruta, M. Hayashi, K. Kataoka, J. Biomater. Sci., Polym. Ed. 1996, 8, 77.

[7] P. B. van Wachem, C. M. Vreriks, T. Beugeling, J. Feijen, A. Bantjes, J. P. Detmers, W. G. van Aken, J. Biomed. Mater. Res. 1987, 21, 701.

[8] S. P. Massia, J. A. Hubbell, Ann. NY Acad. Sci. 1990, 589, 261.

[9] S. P. Massia, J. A. Hubbell, J. Biomed. Mater. Res. 1991, 25, 223.

[10] B. Jeschke, J. Meyer, A. Jonczyk, H. Kessler, P. Adamietz, N. M. Meenen, M. Kantlehner, C. Goepfert, B. Nies, Biomaterials 2002, 23, 3455.

[11] F. Grinnell, C. H. Ho, T. L. Tuan, J. Cell. Sci. 1988, 90, 201.

[12] A. Dekker, A. A. Poot, J. A. van Mourik, M. P. Workel, T. Beugeling, A. Bantjes, J. Feijen, W. G. van Aken, Thromb. Haemostasis 1991, 66, 715.

[13] N. M. Green, Adv. Protein Chem. 1975, 29, 85.

[14] M. Wilchek, E. A. Bayer in: "Methods in Enzymology", Vol. 184, M. Wilchek, E. A. Bayer, Eds., Academic Press, Inc., San Diego, CA 1990, p. 5.
[15] A. A. Bogdanov, Jr., L. V. Gordeeva, B. A. Baibakov, L. B. Margolis, V. P. Torchilin, J. Cell. Physiol. 1991, 147, 182.

[16] P. Didisheim, J. T. Watson. in: "Biomaterials Science: An Introduction to Materials in Medicine", B. D. Ratner, A. S. Hoffman, F. J. Schoen, J. E. Lemons, Eds., Academic Press, San Diego, CA 1996, p. 283.

[17] K. P. Walluscheck, G. Steinhoff, S. Kelm, A. Haverich, Eur. J. Vasc. Endovasc. Surg. 1996, 12, 321.

[18] P. Pollara, G. Alessandri, S. Bonardelli, A. Simonini, E. Cabibbo, N. Portolani, G. A. Tiberio, S. M. Giulini, A. Turano, J. Invest. Surg. 1999, 12, 81.

[19] V. D. Bhat, B. Klitzman, K. Koger, G. A. Truskey, W. M. Reichert, J. Biomater. Sci., Polym. Ed. 1998, 9, 1117.

[20] V. D. Bhat, G. A. Truskey, W. M. Reichert, J. Biomed. Mater. Res. 1998, 41, 377.

[21] V. D. Bhat, G. A. Truskey, W. M. Reichert, J. Biomed. Mater. Res. 1998, 40, 57.

[22] B. P. Chan, V. D. Bhat, S. Yegnasubramanian, W. M. Reichert, G. A. Truskey, Biomaterials 1999, 20, 2395.

[23] A. B. Mathur, B. P. Chan, G. A. Truskey, W. M. Reichert, J. Biomed. Mater. Res. 2003, 66A, 729.

[24] A. B. Mathur, G. A. Truskey, W. M. Reichert, J. Biomed. Mater. Res. 2003, 64A, 155.

[25] U. Wojda, P. Goldsmith, J. L. Miller, Bioconjugate Chem. 1999, 10, 1044

[26] Y. J. Kim, R. L. Sah, J. Y. Doong, A. J. Grodzinsky, Anal. Biochem. 1988, 174, 168.

[27] Y. S. Nam, J. J. Yoon, J. G. Lee, T. G. Park, J. Biomater. Sci., Polym. Ed. 1999, 10, 1145.

[28] B. Alberts, D. Bray, J. Lewis, M. Raff, K. Roberts, J. D. Waston, "Molecular Biology of the Cell", 3rd edition, Garland Publishing, Inc., New York 1994.

[29] S. C. Kuo, D. A. Lauffenburger, Biophys. J. 1993, 65, 2191.

[30] E. A. Bayer, M. Wilchek, Methods Biochem. Anal. 1980, 26, 1. 